\title{
Purification and Some Properties of Candida albicans Exo-1,3- $\beta$-glucanase
}

\author{
By MARÍA MOLINA, ROSA CENAMOR, MIGUEL SANCHEZ AND \\ CÉSAR NOMBELA* \\ Departamento de Microbiologia, Facultad de Farmacia, Universidad Complutense, \\ 28040 Madrid, Spain
}

(Received 11 July 1988; revised 18 October 1988; accepted 25 October 1988)

\begin{abstract}
An exo-1,3- $\beta$-glucanase was purified from blastoconidia of Candida albicans 1001. The purified enzyme appeared as a single protein band by PAGE, and split into two subunits $\left(M_{\mathrm{r}}\right.$ approximately 63000 and 44000) when analysed by SDS-PAGE. The pI of the enzyme was 4 and a $K_{\mathrm{m}}$ of $1.7 \mathrm{mg} \mathrm{m}^{-1}$ was estimated for laminarin as substrate. Despite its very reduced activity on the synthetic substrate $p$-nitrophenyl $\beta$-D-glucoside, $C$. albicans exo-1,3- $\beta$-glucanase hydrolysed 1,3- $\beta$-glucan by an exo-splitting mechanism and was inhibited by glucono- $\delta$-lactone and by $\mathrm{Hg}^{2+}$ and $\mathrm{Ag}^{+}$cations. The active exo-glucanase was mainly located in the periplasm, but it was also present inside the cytoplasmic membrane in small amounts and was secreted into the culture medium. The electrophoretic mobility of the enzyme from all three locations was the same.
\end{abstract}

\section{INTRODUCTION}

Candida albicans is a dimorphic yeast of medical importance. The basis of dimorphism in this species and its potential relationship to pathogenicity (Odds, 1985) are two major aspects of interest in research on $C$. albicans. Glucan, with either $1,3-\beta$ - or $1,6-\beta$-linkages, represents the main structural component of the cell wall of C. albicans (Sullivan et al., 1983; Gopal et al., 1984) and this suggests an important role for glucanases as autolysins during growth and morphogenesis of this organism.

Although all fungal species that contain glucan in their cell walls apparently produce glucanases, there is a striking diversity in the different glucanase systems that have so far been characterized. Variations in the number of enzymes and the mode of action and properties of these proteins in different fungi make it difficult to present a unifying picture of the system. Therefore, a detailed characterization of the relevant enzymes is required to understand the biological role of glucanases as autolysins in each particular organism.

We have reported (Molina et al., 1987) that the bulk of glucanase activity produced by $C$. albicans consists of an exo-1,3- $\beta$-glucanase that, unlike most exo-hydrolysing enzymes, has an almost negligible activity on the synthetic substrate $p$-nitrophenyl $\beta$-D-glucoside (pNPG). In this communication we present the subunit structure of this enzyme and its most relevant properties.

\section{METHODS}

Organism, media and growth conditions. C. albicans 1001 from the Spanish Type Culture Collection (recently deposited as ATCC 64385) was used throughout this study. Yeast cells were grown in YED medium (containing $15 \mathrm{~g}$ Difco yeast extract and $30 \mathrm{~g}$ glucose per litre), by shaking at $28^{\circ} \mathrm{C}$ in an orbital incubator (Gallenkamp). Cells were usually harvested at the late exponential phase of growth, after approximately $15 \mathrm{~h}$ incubation.

Enzyme preparations. The preparation was obtained from 10 lof culture (containing approximately $2 \times 10^{8}$ cells

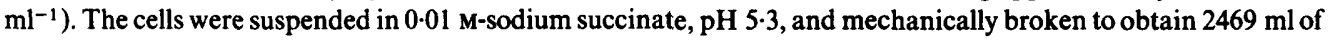

Abbreviations: MUG, 4-methylumbelliferyl $\beta$-D-glucoside; pNPG, $p$-nitrophenyl $\beta$-D-glucoside. 
cell-free extract; supernatant fluid $(40000 \mathrm{~g})$ from this crude extract was prepared essentially as described previously (Molina et al., 1987), with the exception that dialysis was done before, and not after, centrifugation of the extracts. These preparations were stored frozen at $-20^{\circ} \mathrm{C}$. To precipitate the enzyme, solid ammonium sulphate (Merck) was added to $60 \%$ saturation, and the solution maintained for $1 \mathrm{~h}$ at $4{ }^{\circ} \mathrm{C}$. Precipitated proteins were pelleted by centrifugation $(30000 \mathrm{~g}$ ), dissolved in a small amount of $0.01 \mathrm{M}$-sodium succinate, $\mathrm{pH} 5 \cdot 3$, and dialysed overnight against the same buffer.

DEAE-Biogel A (Bio-Rad) chromatography was done in a column $(3.2 \times 45 \mathrm{~cm})$ equilibrated with the same buffer; retained proteins were eluted with a linear $\mathrm{NaCl}$ gradient $(0$ to $0.3 \mathrm{M})$ in the same buffer at a flow rate of $12 \mathrm{ml} \mathrm{h}^{-1}, 2.5 \mathrm{ml}$ fractions being collected.

Sephadex G-75 gel filtration was done on a column $(2.5 \times 87.5 \mathrm{~cm})$ previously equilibrated with $0.025 \mathrm{M}$-sodium succinate, pH 5.3. Before gel filtration, the enzyme-containing fraction from ion exchange chromatography was concentrated by dialysis against polyethylene glycol 20000 (at $4{ }^{\circ} \mathrm{C}$ ) and then dialysed against $0.025 \mathrm{M}$-sodium succinate, pH 5.3, before applying it to the column. Elution was with the same buffer at a flow rate of $2 \mathrm{ml} \mathrm{h}^{-1}$, $1 \mathrm{ml}$ fractions being collected. In all cases, the protein contents of column eluates were estimated from absorbance measured with an ultraviolet monitoring system (ISCO UA5 model).

Gel electrophoresis. Analytical PAGE under non-dissociating conditions was done in $10 \%(\mathrm{w} / \mathrm{v})$ polyacrylamide gels at pH 8.9 according to the method described by Ornstein \& Davis (1964). Enzyme activities were detected on the gels either by overlaying them with the fluorogenic substrate 4-methylumbelliferyl $\beta$-D-glucoside (MUG) $(0.2 \%$ in $0.01 \mathrm{M}$-sodium succinate, $\mathrm{pH} 5.3$, with $1 \%$ agar $)$ or by cutting the gel into $1 \mathrm{~mm}$ slices, and checking activity on laminarin or pNPG. Hydrolysis of MUG was observed, after 30 to $60 \mathrm{~min}$ at $37^{\circ} \mathrm{C}$, by UV illumination.

Analytical PAGE was also done under dissociating conditions with the same type of gels but in the presence of SDS and $\beta$-mercaptoethanol as described by Laemmli (1970). In all cases, protein bands were visualized by staining either with Coomassie brilliant blue or with silver nitrate (Merrill et al., 1982).

Preparative gel electrophoresis was done in an Elfe TM electrophoresis unit (Genofit). Samples were applied to a $10 \%(\mathrm{w} / \mathrm{v})$ polyacrylamide column and run for $6 \mathrm{~h}$ at $120 \mathrm{~V}$ and $4{ }^{\circ} \mathrm{C}, 0.3 \mathrm{ml}$ fractions being collected.

Isoelectric focusing. Analytical electrofocusing of the purified enzyme was done in an LKB-focusing system. The gradient was formed in a $7.5 \%$ polyacrylamide gel of $0.2 \mathrm{~mm}$ thickness, using ampholine carrier ampholytes for two different $\mathrm{pH}$ ranges, a wider one ( 3.5 to 9.5$)$ and a narrower one (2.5 to 5). Focusing was done for 70 min and $120 \mathrm{~min}$ respectively, at $1120 \mathrm{~V}$. Protein bands were stained with silver nitrate and enzyme activity detected with MUG, as described above.

Other determinations. Assays of 1,3- $\beta$-glucanase activity against laminarin and of $\beta$-glucosidase based on the hydrolysis of pNPG were as described previously (Molina et al., 1987); 1 unit of activity (U) was defined as the amount of enzyme which released $1 \mathrm{nmol}$ of the measured reaction product $\mathrm{min}^{-1}$ under the conditions of the reaction. The products generated by laminarin hydrolysis were identified by TLC using D-glucose as a standard.

Chemicals. Laminarin, pNPG and MUG were purchased from Sigma, Sephadex G-75 from Pharmacia, DEAE-Biogel, acrylamide and bis-acrylamide from Bio-Rad and glusulase from Dupont. All other reagents were of analytical grade from commercial sources.

\section{RESULTS}

In order to analyse the biochemical characteristics of $C$. albicans exo-1,3- $\beta$-glucanase, the enzyme was purified from supernatants of cell-free extracts (Table 1). A highly purified preparation was obtained after the gel filtration step, so that a single protein band was observed when the preparation was analysed by non-dissociating PAGE and stained with Coomassie blue (data not shown). However, similar gels stained by using the more sensitive silver nitrate method revealed the presence of some impurities (Fig. 1a). The active exo-1,3- $\beta$-glucanase was identified as the most prominent band in this preparation by its ability to hydrolyse laminarin assayed after slicing the corresponding part of the gel (Fig. 1d). Although the action of this glucanase on synthetic glucosides is very limited (Molina et al., 1987), the MUG hydrolysis assay was sensitive enough to confirm this protein band as the active glucanase (Fig. $1 c$ ).

The enzyme was further purified by preparative gel electrophoresis to yield a preparation showing a single protein band in non-dissociating gels stained with silver nitrate (Fig. $1 b$ ). The pure enzyme split into two protein bands when analysed by SDS-PAGE (Fig. 2) indicating that the active protein consists of two subunits. The $M_{\mathrm{r}}$ of the subunits was estimated in SDS-PAGE, by comparison with appropriate standards, to be 63000 and 44000 respectively, and given the apparent $1: 1$ stoichiometry of the two subunits the $M_{\mathrm{r}}$ of the intact enzyme must be 107000 daltons or a multiple of it. It is not possible to estimate the $M_{\mathrm{r}}$ of the native enzyme from gel 
(a)

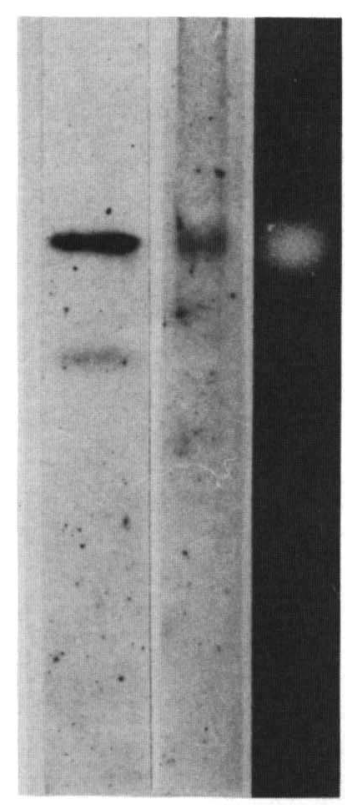

Fig. 1 (d)

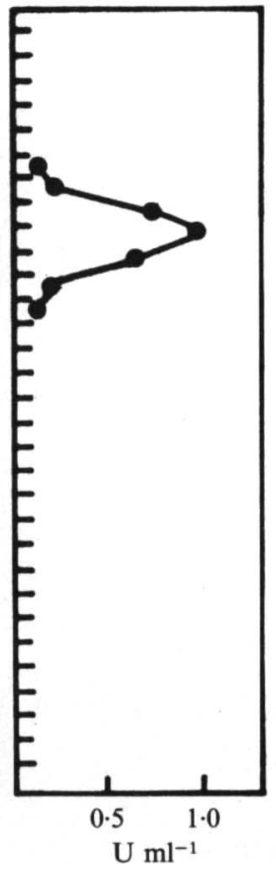

$10^{-3} \times$

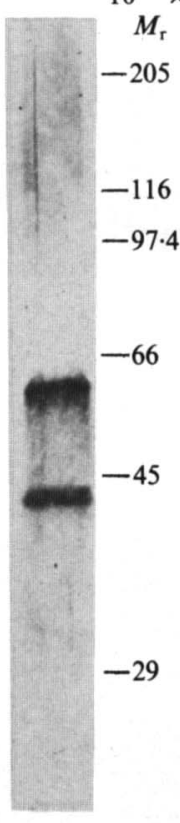

Fig. 2

pI

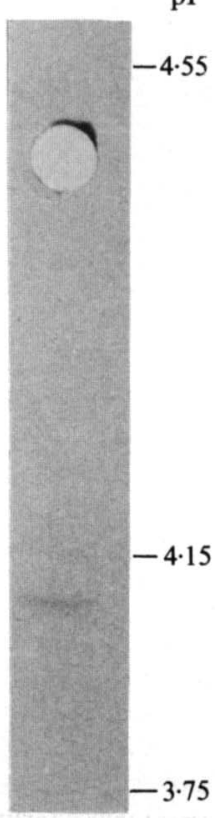

Fig. 3

Fig. 1. PAGE of purified exo-1,3- $\beta$-glucanase (after the gel filtration step: see Table 1) (a) stained with silver nitrate, $(c)$ assayed for activity against MUG and $(d)$ against laminarin after slicing the gel. (b) PAGE of the pure preparation (after preparative gel electrophoresis) stained with silver nitrate. The amounts of protein loaded were $4 \mu \mathrm{g}$ in $a, b$ and $d$ and $1 \mu \mathrm{g}$ in $c$.

Fig. 2. SDS-PAGE of purified exo-1,3- $\beta$-glucanase (after preparative gel electrophoresis), stained with silver nitrate. Values on the right indicate mobilities of the $M_{\mathrm{r}}$ standards.

Fig. 3. Analytical electrofocusing of the purified exo-1,3- $\beta$-glucanase $(1 \mu \mathrm{g})$ stained with silver nitrate. Values on the right represent pI standards.

Table 1. Purification of the exo-1,3- $\beta$-glucanase from cell-free extracts of $C$. albicans

\begin{tabular}{|c|c|c|c|c|c|}
\hline Purification step & Total units* & $\begin{array}{l}\text { Volume } \\
(\mathrm{ml})\end{array}$ & $\begin{array}{l}\text { Total } \\
\text { protein } \\
\text { (mg) }\end{array}$ & $\begin{array}{c}\text { Specific } \\
\text { activity } \\
{[\mathrm{U}(\mathrm{mg}} \\
\left.\text { protein })^{-1}\right]\end{array}$ & $\begin{array}{l}\text { Purification } \\
\text { (-fold) }\end{array}$ \\
\hline \multicolumn{6}{|l|}{$x$ tract $(48000 \mathrm{~g}$} \\
\hline ant fluid) & $62838(100)$ & 2469 & 7130 & $8 \cdot 8$ & $1 \cdot 0$ \\
\hline ind thawing & $69213(110)$ & 2385 & 3649 & 19 & $2 \cdot 1$ \\
\hline um sulphate precipitation & $45855(72 \cdot 9)$ & $445 \cdot 5$ & 461.9 & $99 \cdot 3$ & $11 \cdot 3$ \\
\hline iogel A & $39151(62 \cdot 3)$ & 98 & $24 \cdot 5$ & 1598 & $181 \cdot 4$ \\
\hline centration & $27081(39 \cdot 1)$ & $9 \cdot 4$ & 10.8 & 2507 & $284 \cdot 6$ \\
\hline G-75 gel filtration & $24486(35.4)$ & 108 & 1.9 & 12622 & $1432 \cdot 7$ \\
\hline
\end{tabular}

* Figures for percentage yield are shown in parentheses.

filtration chromatography because activity is significantly retarded and elutes with an apparent $M_{\mathrm{r}}$ much less than 100000 (Molina et al., 1987), probably due to an affinity for the Sephadex matrix that is also exhibited by other glucanases (Sanchez et al., 1982a). However, the electrophoretic mobility of $C$. albicans exo-glucanase in non-dissociating $10 \%$ polyacrylamide gels, when compared to that of Saccharomyces cerevisiae exo-glucanase of similar isoelectric point, indicated that the $M_{\mathrm{r}}$ could be close to 100000 (data not shown). This would favour the idea of the enzyme consisting of two subunits with the indicated $M_{\mathrm{r}}$ values. 
(a)

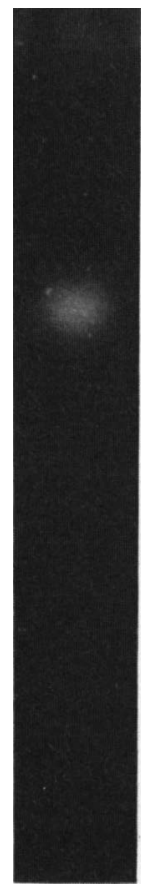

(b)

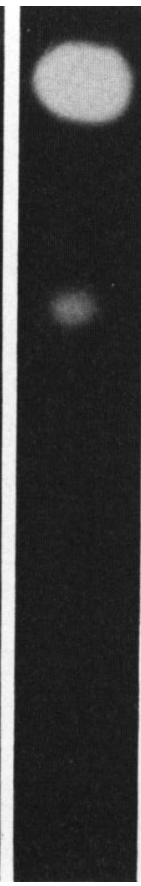

(c)

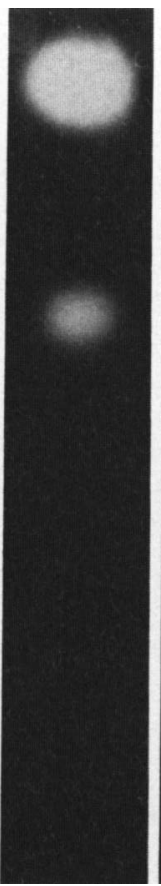

(d)

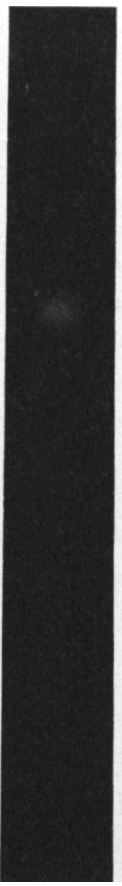

(e)

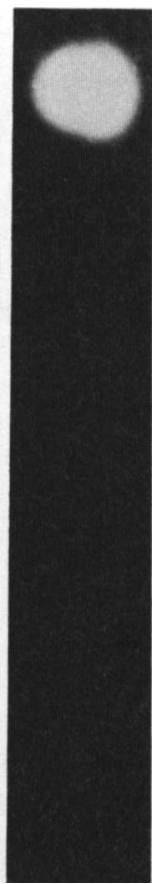

Fig. 4. PAGE analysis and MUG-hydrolysing activity of exo-1,3-glucanase in different cellular fractions. (a) Purified preparation (after gel filtration: see Table 1); (b) protoplast lysates; (c) cell-free extracts; $(d)$ culture fluids; $(e)$ partially purified $C$. albicans $\beta$-glucosidase.

The properties and mode of action of the enzyme were studied with the highly purified preparation obtained after the gel filtration step (Table 1). Optimum $\mathrm{pH}$ for activity was in the range of $5 \cdot 5$ to $6 \cdot 0$, at least a $70 \%$ reduction in activity being observed at $\mathrm{pH}$ values lower than $5 \cdot 0$ or higher than $7 \cdot 0$. For short incubation periods $(15 \mathrm{~min})$ the apparent optimum temperature was $50{ }^{\circ} \mathrm{C}$, but preincubation of the enzyme (for $30 \mathrm{~min}$ ) at this temperature reduced its activity by $50 \%$ when it was assayed subsequently. The purified $\beta$-glucanase preparation was active against laminarin (1,3- $\beta$-glucan) but inactive on pustulan (1,6- $\beta$-glucan). TLC of the reaction products released from laminarin showed that glucose was the only sugar produced. Consistent with this, periodate-oxidized laminarin (i.e. substrate with modified chain ends) (Goldstein et al., 1965) was not hydrolysed. This observation clearly indicated an exohydrolytic mode of action for this $\beta$-glucanase; however, in contrast to what is usually observed with exo-1,3- $\beta$ glucanases, its activity against the synthetic substrate pNPG was very low (approximately $4 \%$ of the activity against laminarin).

The same highly purified exo-1,3- $\beta$-glucanase preparation was used for kinetic and inhibition studies. A $K_{\mathrm{m}}$ of $1.7 \mathrm{mg} \mathrm{ml}^{-1}$ was estimated, using laminarin as substrate. As with other glucanases (Bull, 1967), the enzyme was efficiently inhibited by glucono- $\delta$-lactone: a concentration of $10 \mathrm{~mm}$ caused $86 \%$ inhibition. Concentrations of $0.5 \mathrm{~mm}-\mathrm{Hg}^{2+}$ and $1 \mathrm{~mm}-\mathrm{Ag}^{+}$ caused $100 \%$ and $50 \%$ inhibition respectively. Finally, a pI of approximately 4 was measured for the active glucanase band in the purified preparation (Fig. 3).

The bulk of the cell-bound exo-glucanase of $C$. albicans is located in the periplasm (Molina $e t$ al., 1987). Electrophoresis in non-dissociating gels, followed by detection of the active glucanase by hydrolysis of MUG was used to compare exo-glucanase in different cell fractions. The purified enzyme showed a single active band (Fig. $4 a$ ); a band of the same mobility was detected in cell-free extracts (Fig. $4 c$ ), concentrated protoplast lysates (Fig. $4 b$ ) (in this case of a very low 
intensity) and culture medium (Fig. $4 d$ ). The first two preparations displayed another much more intense band of MUG-hydrolysing activity which corresponded to a distinct $\beta$-glucosidase enzyme (Fig. $4 e$ ) that was not detected either in culture medium samples (Fig. $4 d$ ) or as a protoplast secretion product (data not shown), confirming the cytoplasmic location of $C$. albicans $\beta$-glucosidase (Polacheck et al., 1987).

\section{DISCUSSION}

Detailed characterization of $\beta$-glucanases in several fungal species indicates that these enzyme systems are complex with regard to the number of enzymes involved, and diverse from the point of view of differences between species. This complexity is most clearly illustrated by the studies done on $S$. cerevisiae. At least two 1,3- $\beta$-glucan degrading enzymes, which can be detected in protoplast lysates and among protoplast secretion products, can be distinguished from the two glucanases present in cell-free extracts and in the culture medium (Cenamor et al., 1987). The complexity and diversity obscure the essential role(s) of the glucanase system in species bearing glucan as their major wall component. The necessity for such a complex system and the evolutionary divergence that it shows remain to be explained. Moreover, the difficulty of using the physiological substrates of these enzymes is a limitation on investigation of the system.

The 1,3- $\beta$-glucanase system of $C$. albicans is no exception to this general rule. The production of more than one $\beta$-glucanase has been documented for some strains and strain differences are the likely explanation for several discrepancies in the experimental results from different laboratories (Notario, 1982; Ram et al., 1984). The most abundant 1,3- $\beta$-glucanase of $C$. albicans 1001 is clearly the exo-hydrolysing enzyme that we reported previously (Molina et al., 1987) and have now further characterized. From the point of view of its kinetic properties (with laminarin as substrate), optimum $\mathrm{pH}$ and inhibition by glucono- $\delta$-lactone, it does not differ very much from other exo-1,3- $\beta$-glucanases that have been analysed in detail. Examples of these are one of the exo-glucanases of $S$. cerevisiae (Sanchez et al., 1982b) and exo-glucanases of Pichia polymorpha (Villa et al., 1975), Candida utilis (Villa et al., 1976) and Kluyveromyces phaseolosporus (Villa et al., 1978). However, its greatly reduced activity on synthetic glucosides $(4 \%$ of the activity on laminarin) and its subunit structure are properties not shared by most of the other known major exo-glucanases produced by fungal species, confirming the diversity of these enzyme systems among different species. Moreover, the capacity of the enzyme to hydrolyse synthetic glucosides such as pNPG also seems to vary between strains of $C$. albicans (Olivero \& Larriba, personal communication).

The active exo-1,3- $\beta$-glucanase could be detected in small amounts in protoplast lysates, and was secreted into the periplasmic space and culture medium without any apparent modification affecting its electrophoretic mobility. This is consistent with the notion that the active enzyme is produced inside the membrane and exported to the outside medium. The previously suggested possibility of the enzyme being activated from an inactive precursor (Molina et al., 1987) is also compatible with these findings and is currently being considered in this laboratory, as one of the properties to be studied by a more extensive characterization that includes cloning the gene.

This investigation was supported by grant BT020/86 from Comisión Interministerial de Ciencia y Tecnología.

\section{REFERENCES}

Bull, A. T. (1967). The enzymatic degradation of $\beta$ glucans. International Biodeterioration Bulletin 3, 3-6.

Cenamor, R., Molina, M., Galdona, J., Sanchez, M. \& Nombela, C. (1987). Production and secretion of Saccharomyces cerevisiae $\beta$-glucanases: differences between protoplast and periplasmic enzymes. Journal of General Microbiology 133, 619-628.

GoldsteIn, I. J., HAY, G. W., LEWIS, B. A. \& SMITH, F. (1965). Controlled degradation of polysaccharides by periodate oxidation reduction and hydrolysis. Methods in Carbohydrate Chemistry 5, 361-369.

Gopal, P. K., Shepherd, M. G. \& Sullivan, P. A. (1984). Analysis of wall glucan from yeast, hyphal and germ tube forming cells of Candida albicans. Journal of General Microbiology 130, 3295-3301.

LAEMMLI, U. K. (1970). Cleavage of structural proteins during the assembly of the head of bacteriophage T4. Nature, London 227, 680-685. 
Merril, C. R., Goldman, D. \& van Keuren, M. L. (1982). Simplified silver protein detection and image enhancement methods in polyacrylamide gels. Electrophoresis 3, 17-21.

Molina, M., Cenamor, R. \& Nombela, C. (1987). Exo-1,3- $\beta$-glucanase activity in Candida albicans: effect of the yeast-to-mycelium transition. Journal of General Microbiology 133, 609-617.

NotaRIO, V. (1982). $\beta$-Glucanases from Candida albicans: purification, characterization and the nature of their attachment to the cell wall components. Journal of General Microbiology 128, 747-759.

OdDs, F. C. (1985). Morphogenesis in Candida albicans. CRC Critical Reviews in Microbiology 12, 45-80.

ORnSTEIN, L. \& DAvis, B. J. (1964). Disk electrophoresis. I. Background and theory. Annals of the New York Academy of Sciences 121, 321-349.

Polacheck, I., Melamed, M., Bercovier, H. \& SALKIN, I. F. (1987). $\beta$-Glucosidase in Candida albicans and its application to yeast identification. Journal of Clinical Microbiology 25, 907-910.

Ram, S. P., Romana, L. K., Shepherd, M. G. \& Sullivan, P. A. (1984). Exo-1,3- $\beta$-glucanase, autolysin and trehalase activities during growth and germ tube formation in Candida albicans. Journal of General Microbiology 130, 1227-1236.
Sanchez, A., Nebreda, A. R. \& Villa, T. G. (1982 $a$ ). Self-associating properties of yeast exo- $\beta$-glucanase are dependent on the ionic strength. FEBS Letters 145, 213-216.

Sanchez, A., Villanueva, A. R. \& Villa, T. G. $(1982 b)$. Effect of tunicamycin on exo-1,3- $\beta$-glucanase synthesis and secretion by cells and protoplasts of Saccharomyces cerevisiae. Journal of General Microbiology 128, 3051-3060.

Sullivan, P. A., Chiew, Y. Y., Molloy, C., TempleTON, M. D. \& SHEPHERD, M. G. (1983). An analysis of the metabolism and cell wall composition of Candida albicans during germ tube formation. Canadian Journal of Biochemistry 125, 209-212.

Villa, T. G., Notario, V. \& Villanueva, J. R. (1975). $\beta$-Glucanases of the yeast Pichia polymorpha. Archives of Microbiology 104, 201-206.

Villa, T. G., Notario, V., Benitez, T. \& VillaNUEva, J. R. (1976). Purification of an exo-1,3- $\beta$ glucanase from Candida utilis. Canadian Journal of Biochemistry 54, 927-934.

Villa, T. G., Lachance, M. A. \& Phaff, H. J. (1978). $\beta$-Glucanases of the yeast Kluyveromyces phaseolosporus: partial purification and characterization. Experimental Mycology 2, 12-25. 